\title{
Effects of Shrimp-Vegetable Rotation on Microbial Diversity and Community Structure in Pond Sediment
}

\author{
Ke Li", Duo Chen", Zhen Huang, Jin Fu, Youqiang Chen, Ting Xue, \\ Ting Zhang, Gang Lin*
}

The Public Service Platform for Industrialization Development Technology of Marine Biological Medicine and Products of the State Oceanic Administration, Center of Engineering Technology Research

for Microalga Germplasm Improvement of Fujian, Fujian Key Laboratory of Special Marine Bioresource Sustainable Utilization, Key Laboratory of Developmental and Neural Biology, Southern Institute of Oceanography,

College of Life Sciences, Fujian Normal University, Fuzhou, China

Received: 24 July 2021

Accepted: 20 November 2021

\begin{abstract}
Rotation is an important method to improve land utilization and the economic benefits of aquaculture. Shrimp vegetable rotation is a new farming and planting rotation model. The purpose of this study is to reveal the community of microorganisms in pond sediments under shrimp-vegetable rotation and provide theoretical basis for maintaining soil fertility. In this study, three groups were set: cultivated areas (CC, shrimp-vegetable rotation mode), uncultivated area (CG, shrimp farming and fallow mode), and flooded area (CS, continuous shrimp farming mode). Diversity and community composition of microorganism communities were displayed using real-time PCR and high-throughput sequencing platforms. The results showed that the shrimp-vegetable rotation significantly reduced the content of total nitrogen (TN, compared with CG and CS, CS has dropped by about $50 \%$ and $80 \%$, respectively),total carbon (TC, compared with CS, CS has dropped by about $50 \%$ and $70 \%$, respectively) and total phosphorus (TP, compared with CG and CS, CS has dropped by about $60 \%$ ) in the sediment and removing excess nutrients in the aquaculture environment. The relative abundance of Proteobacteria and Gemmatimonadetes phylum was significantly higher in the CC and CG groups than in CS. And the majority of denitrifying bacteria are concentrated in the Proteobacteria that increased abundance of denitrifying bacteria confirms results of increased copy number of nosZ and phoD genes. Herein, a conclusion was drawn that shrimp-vegetable rotation had stronger restoration ability of soil bacterial diversity and soil fertility than the other two farming mode. Also, the rotation mode
\end{abstract}

\#Ke Li and Duo Chen have contributed equally to this work.

*e-mail: lgffz@fjnu.edu.cn 
promoted a good ammonia nitrogen cycle. This study will provide a scientific basis and data support for the application of shrimp vegetable rotation.

Keywords: shrimp-vegetable rotation, soil microbial community, nitrification, denitrification

\section{Introduction}

Rotation is an ancient farming practice, which has been used for thousands of years in agriculture and is still used today [1]. The shrimp-vegetable rotation is an eco-agricultural system that combines vegetable cultivation and shrimp farming, which brings considerable economic benefits to the grid and saves water and land resources. Compared with individual vegetable cultivation, the system composed of aquatic animal farming such as fish, shrimp, and duck had many advantages [2-5]. Pond sediment is an important part of the pond ecosystem [6]. Due to long-term cultivation, a large amount of feed input and organic matter and biological nutrients formed by shrimp metabolites are accumulated in the pond bottom [7]. The oxidative decomposition requires oxygen, which affects the dissolved oxygen in the aquaculture water, and also easily decomposes to produce toxic substances, such as methane, nitrous nitrogen, hydrogen sulfide, ammonia, etc.

The restoration technology of the aquaculture environment includes physical restoration, chemical restoration and biological restoration, among which biological restoration has the advantages of low cost, simple processing, and high safety. Considering the advantages mentioned above, people pay more attention to the research of bioremediation technology in water environment restoration. Biological restoration has been gradually applied to aquaculture pollution treatment by dealing with organic pollution of sediment and eutrophication of water bodies. Microbial denitrification is mainly accomplished through nitrification and denitrification. Denitrification plays a vital role in soil nitrogen conversion as a component of soil nitrogen cycle [8-10]. Denitrification is a process in which microorganisms use nitrogen oxides as electron acceptors to generate energy. This process consists of a 4-step reaction [11]: $\mathrm{NO}_{3}-\mathrm{NO}_{2}-\mathrm{NO}-\mathrm{N}_{2} \mathrm{O}-\mathrm{N}_{2}$. The intermediate process produces gases such as carbon monoxide and nitrous oxide, causing nitrogen loss and causing a series of environmental problems [12]. At present, researches on denitrifying bacteria are mainly concentrated in marine sediments, estuary sediments, marine water bodies, soils, and wetlands [13-17], but studies about molecular ecology of denitrifying microorganisms in aquaculture environment remain limited.

The shrimp-vegetable rotational farming system model is a new application model of planting and breeding proposed in recent years, which can fully utilize the shallow water environment and winter idle period of shrimp ponds in these coastal tidal flats and organically combine agriculture with aquaculture to maximize the utilization and productivity rates of shrimp ponds [18, 19]. However, little was known about the changes of microorganisms in soil in the shrimp-vegetable rotational farming system. Revealing its mechanism can promote the scientific application and improvement of the shrimp-vegetable rotation system. The purpose of this study is to reveal the community of microorganisms in pond sediments under shrimp-vegetable rotation, provide theoretical basis for maintaining soil fertility, and screen the key influencing factors that affect the application of the shrimp and vegetable rotation system. And we hypothesized that shrimp vegetable rotation can accelerate the ammonia nitrogen cycle and bring positive effects on soil microorganisms. The results revealed the changes in the structure and diversity of microbial communities and enriched the theory of denitrifying microorganisms in shrimp-vegetable rotation system. This study will provide a theoretical basis and data support for increasing aquatic product output.

\section{Material and Methods}

\section{Ethics Statement}

Shrimp were collected from the Fujian Dongsheng Agricultural Comprehensive Development Co. Ltd. All experiments were performed according to the Guide for the Care and Use of Laboratory Animals of China. Our studies were approved by the Committee on the Ethics of Animal Experiments of the Fujian Normal University.

\section{Study Design and Sampling}

A pond in the Fuqing Comprehensive Experimental Station of the National Shrimp and Crab Industrial System was used as the test pond, which is located in Xiali Village, Yuxi Town, Fuqing City, Fujian Province $\left(25^{\circ} 33^{\prime} 54.5^{\prime \prime} \mathrm{N} 119^{\circ} 17^{\prime} 25.9^{\prime \prime} \mathrm{E}\right)$ (Fig. S1). The pond was divided into three areas: cultivated area (group $\mathrm{CC}$ ), uncultivated area (group CG) and flooded area (group CS). For CC group, cabbage and cauliflower were planted in the cultivation area according to the cultivation process (when no vegetables were planted, shrimp culture was carried out in the conventional way); For CG group, it was treated according to the traditional cultivation method, and the water body in the pond was drained only after shrimp harvesting; For CS group, the flooded area was submerged by water in the lowlying area of the pond and without vegetables planting 
or shrimp farming here. The idea of experiment design is shown in Fig. 1.

In the process of vegetable planting, no chemical fertilizers and organic fertilizers were used. In the process of shrimp farming, except for the necessary treatment and prevention of shrimp diseases, no additives were added. For each group, the water area was approximately 20,000 square meters. Soil samples for physical and chemical determination were collected using columnar dredgers at $20 \mathrm{~cm}$ deep. Three sample points were selected randomly in each area. Soil samples of the surface layer (about $2 \mathrm{~cm}$ ) were taken and mixed uniformly for vibriosp detection count analysis. The remaining samples were dried indoors, crushed with a laboratory mill (TAISETE, Tianjin, China) and sieved in $1 \mathrm{~mm}$ Soil Analysis Sieves (SAS).

The sampling was performed for 9 times in April, July, October, December 2017, and January-May 2018, respectively. Among them, April 2017-October 2017 was the shrimp breeding period, and December 2017-June 2018 was the vegetable growing period. The source and area of the sediment required for the microbiological analysis were the same as above. Five samples were taken from each area at the end of planting in May 2018. Each sample was sampled separately using a sterilized plastic tube with a sampling depth of about $5 \mathrm{~cm}$. After sampling, the small tube was quickly placed in a Ziplock bag. Each sample was stored separately and placed in an ice box, and brought back to the laboratory for further processing. In the ultra-clean workbench, the bottom sediments in the same area were evenly mixed and stored at $-80^{\circ} \mathrm{C}$ for analysis.

\section{Measurement of Physicochemical Properties}

Total carbon (TC), total nitrogen (TN), and total phosphorus (TP) were determined using a Smart chem
200 Analyzer (Westco, Italy) with a relative error of $0.1 \%$. Oxidation-reduction potential (ORP)was determined with brightened platinum electrodes [20] inserted in the soil to $5 \mathrm{~cm}$. Also, the soil temperature and $\mathrm{pH}$ are measured with a corresponding thermometer and $\mathrm{pH}$ meter, respectively. Vibrio sp. are harmful bacteria in shrimp farming. For Vibrio sp. counting, the TCBS medium plate counting method was used. $10 \mathrm{~g}$ of the mixed sample was added to $90 \mathrm{ml}$ of distilled water, and the appropriate dilution concentration was used for coating counting.

\section{DNA Extraction and Real-Time PCR}

Soil DNA was extracted from $0.3 \mathrm{Kg}$ of fresh soil using a PowerSoilTM DNA Isolation Kit (MO BIO Laboratories, Carlsbad, CA, USA). The copy number nosZ were determined using a 7500 Real-Time PCR System (Applied Biosystems, Foster City, CA, USA). The universal primer set used for the amplification of nosZ and phoD were $\mathrm{F}$ (CGYTGTTCMTCGACAGCCAG) and R (CGSACCTTSTTGCCSTYGCG). The real-time PCR reaction mixture contained $1.0 \mathrm{uL}$ of template DNA, 2.0uL of primer mixture $(20 \mu \mathrm{M}), 0.2 \mathrm{uL}$ of ROX Reference Dye II $(50 \times), 9.3 \mathrm{uL}$ of water, and $12.5 \mathrm{uL}$ of SYBR Premix Ex Taq II (2×; Takara Bio Inc., Shiga, Japan). The PCR cycling started with an initial denaturation at $95^{\circ} \mathrm{C}$ for $15 \mathrm{~s}$, followed by 40 cycles for $5 \mathrm{~s}$ at $95^{\circ} \mathrm{C}, 30 \mathrm{~s}$ at $56^{\circ} \mathrm{C}, 40 \mathrm{~s}$ at $72^{\circ} \mathrm{C}$, and $30 \mathrm{~s}$ of fluorescence signal collection at $80^{\circ} \mathrm{C}$. A melting curve analysis was performed to examine the specificity of PCR products. A standard curve was constructed using plasmids containing the nosZ fragments. The amplification efficiency was around $85 \%$, and the R2 value of the standard curve was higher than 0.99 .

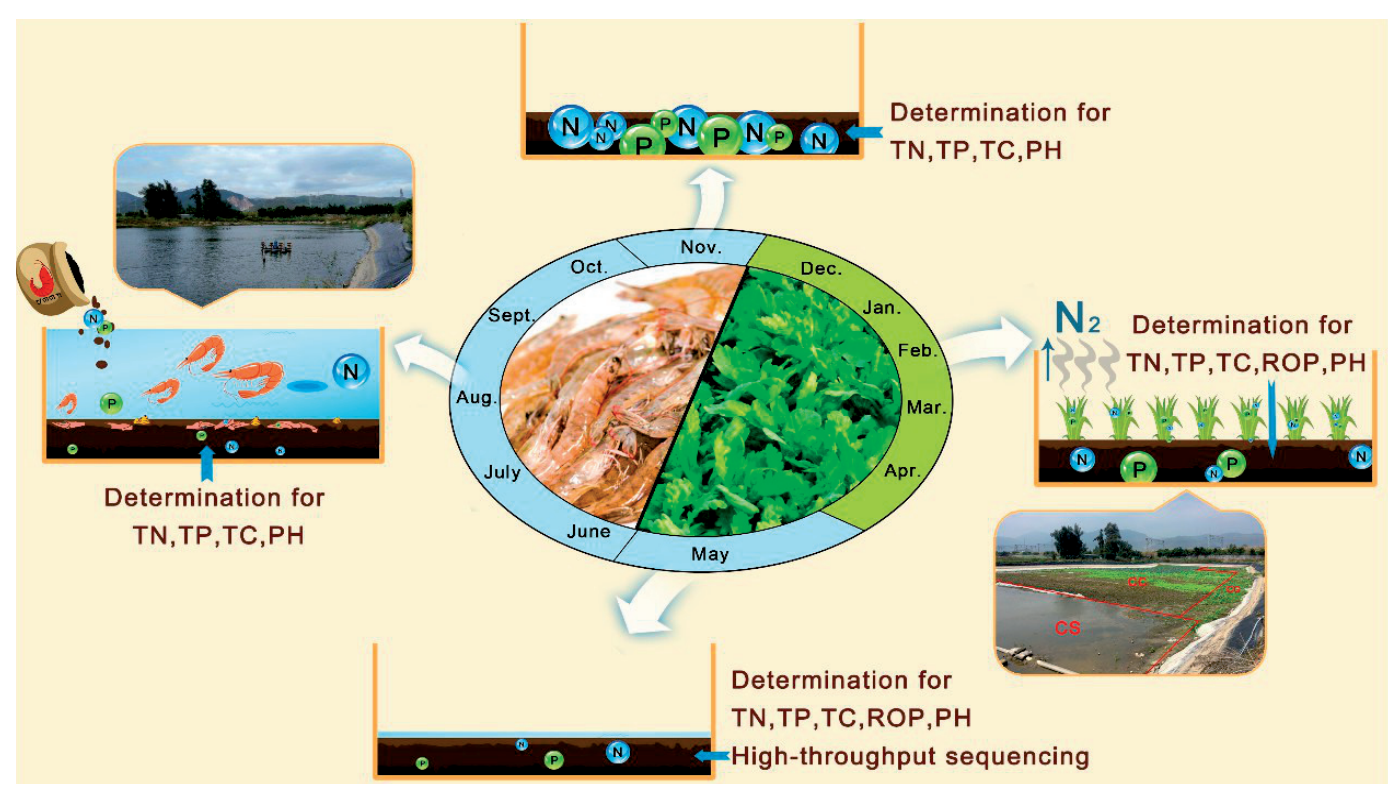

Fig. 1. Simple schematic diagram of experimental design 
Table 1. ORP and $\mathrm{pH}$ trends in three different treatment groups

\begin{tabular}{|c|c|c|c|c|c|c|c|}
\hline & & Dec. 2017 & Jan. 2018 & Feb. 2018 & Mar. 2018 & Apr. 2018 & May 2018 \\
\hline \multirow{3}{*}{ ORP } & CC & 220.33 & 247.67 & 299.00 & 267.33 & 202.00 & 238.33 \\
\cline { 2 - 8 } & CG & 39.33 & 264.00 & 193.67 & 203.67 & 66.00 & 244.00 \\
\cline { 2 - 8 } & $\mathrm{CS}$ & -201.67 & -143.33 & -187.33 & -191.00 & -154.67 & -166.33 \\
\hline \multirow{3}{*}{$\mathrm{pH}$} & $\mathrm{CC}$ & 7.60 & 6.72 & 6.55 & 6.41 & 6.52 & 6.91 \\
\cline { 2 - 9 } & $\mathrm{CG}$ & 7.45 & 6.81 & 6.76 & 6.55 & 6.74 & 6.32 \\
\cline { 2 - 9 } & $\mathrm{CS}$ & 6.89 & 6.91 & 6.86 & 6.72 & 6.21 & 5.95 \\
\hline
\end{tabular}

CC: cultivated area group; CG: uncultivated area group; CS: flooded area groupwork: Oxidation-reduction potential

\section{Library Construction and Sequencing}

To evaluate the bacterial community composition, we amplified the V3 and V4 regions of the bacterial 16s rRNA gene using the primer pairs of 341F (CCTAYGGGRBGCASCAG) /806R (GGACTACNNGGGTATCTAAT). All PCR reactions were carried out with Phusion®High-Fidelity PCR Master Mix (New England Biolabs). PCR products were mixed in equidensity ratios. Then, mixture PCR products were purified with a Qiagen Gel Extraction Kit (Qiagen Inc., Hilden, Germany). Sequencing libraries were generated using TruSeq®DNA PCRFree Sample Preparation Kit (Illumina Inc., San Diego,
USA) following the manufacturer's recommendations and index codes were added. The purified libraries were equimolarly mixed, and $2 \times 250$ bp paired-end sequencing was carried out on an Illumina Hiseq2500 sequencer (Illumina Inc., San Diego, USA).

\section{Data Processing and Analysis}

Raw reads generated from the HiSeq2500 paired-end sequencing were merged together using the Fast Length Adjustment of Short reads (FLASH). A chimera filtering approach UPARSE was employed as the Operational Taxonomic Unit (OTU or phylotype) picking strategy at 97\% sequence similarity. The alpha diversity analysis
A

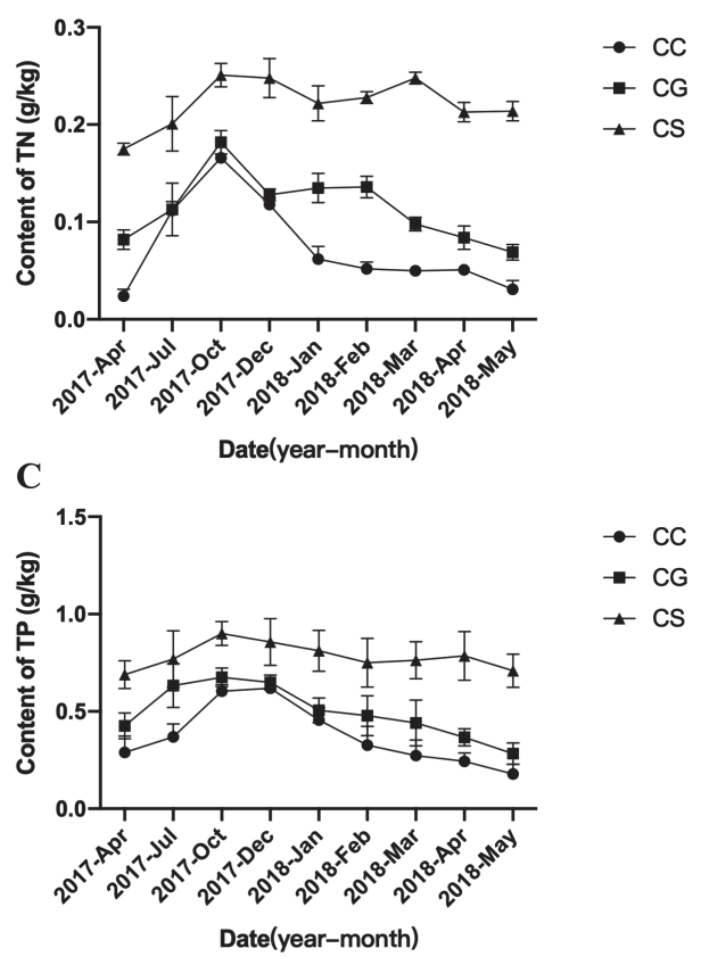

B
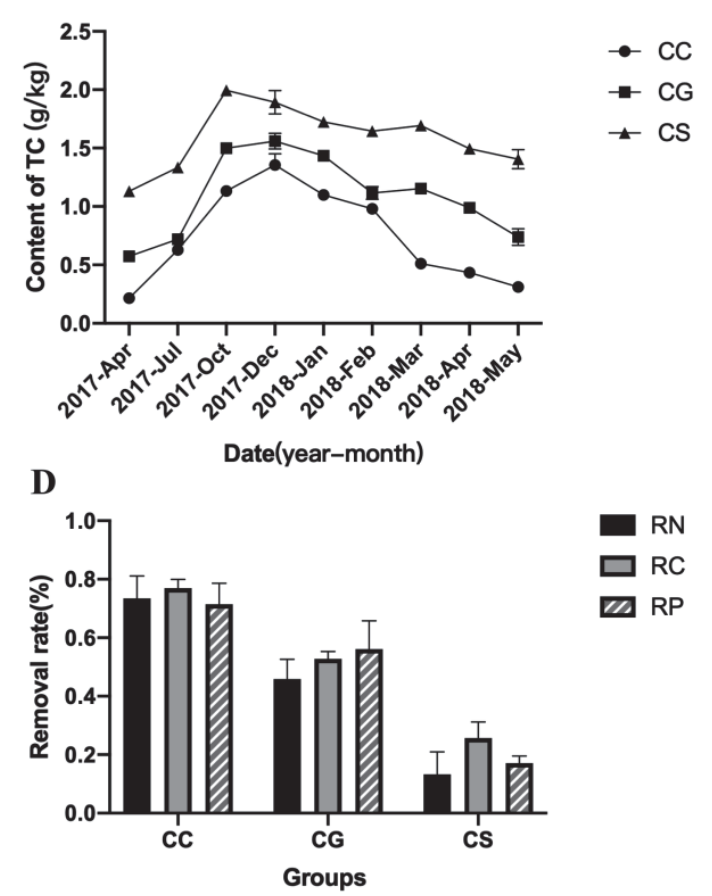

Fig. 2. Total nitrogen (TN), total carbon (TC), total phosphorus (TP) and removal rate in CC, CG and CS groups. (A)-(C) The TN, TC, TP change trends in three groups. (D) The comparison of TN, TC, TP removal rates. (RN: removal rate of TN; RC: removal rate of TC; RP: removal rate of TP). 
(e.g., observed OTUs, abundance-based coverage, Chao, Shannon, Simpson, ACE, coverage, and rarefaction curve) and beta diversity analysis (e.g., non-metric multidimensional scaling, principal component analysis, and principal coordinates analysis) were analyzed by QIIME (v1.8.0) software. The taxonomic identity of all phylotypes was determined using The SILVA ribosomal RNA gene database project. Statistical analyses of the soil chemical parameters and the copy number of nosZ gene and phoD gene were analyzed using GraphPad Prism 6. Comparisons between groups were performed using t test and $\mathrm{P}<0.05$ was defined as the threshold for significant difference.

\section{Results}

\section{Physical and Chemical Properties of Soil under Different Treatments}

The ORP and $\mathrm{pH}$ of different treatment groups at different periods were listed in Table 1. The values of ORP at different periods of the CC group were higher than those of CG and CS groups. However, there was no significant difference in $\mathrm{pH}$ among these three groups. The contents of TN, TC, and TP in the sediment during the shrimp-vegetable rotation system were shown in Fig. 2(a-c). The results showed that the trend of the content of each element with the sampling time is similar. The TN, TC, and TP contents of the CS were significantly higher than the other two groups at each sampling point. The element's content in the three regions showed an upward trend during the shrimp cultivation period and reached a peak at the end of shrimp farming (October 2017). During this period, the content of the element in the $\mathrm{CC}$ region increased most rapidly. At the end of shrimp farming, there was a significant difference between the CC, CG and CS regions $(\mathrm{p}<0.05)$.

The content of $\mathrm{TN}, \mathrm{TC}$, and $\mathrm{TP}$ in the $\mathrm{CC}$ region decreased most significantly after the vegetable planting started in December 2017. However, the content of TN, $\mathrm{TC}$, and TP in the CS region did not change significantly. By comparing the TN, TC and TP content in May 2018 and October 2017, the removal rate of the CC, CG, and $\mathrm{CS}$ regions were shown in Fig. 2d). It can be obtained that the growth of vegetables and weeds has a better effect on the removal of TN, TC, TP in the sediment than that of exposure, and were both better than the flooded area.With the increase of shrimp culture time, the total vibrio densities increased significantly in all three regions and reached the peak at the end of shrimp culture in October 2017. At the end of shrimp culture, there was significant difference between the $\mathrm{CC}$ and CG region $(p<0.05)$, and both extremely significant difference of the CS region $(p<0.01)$. The total vibrio densities in the tillage area remained at a very low level throughout the whole tillage process, it was indicating that the dry environment is not conducive to the growth of Vibrio. From January 2018 to the end of growing vegetables, the total vibrio densities in $\mathrm{CC}$ and CG region remained very low, and the CS region was increased with the increase of temperature. At the end of growing vegetables, there were extremely significant differences between the $\mathrm{CC}$ region and the $\mathrm{CG}$ region or $\mathrm{CS}$ region $(\mathrm{p}<0.01)$ (Fig. $\mathrm{S} 2)$.

\section{Effects of Shrimp-Vegetable Rotation on Soil nosZ and phoD Gene Abundance}

Quantitative analysis of nosZ gene and phoD gene using RT-qPCR technology. The abundance of nosZ gene in CC, CG, CS were 26.38*106copies.g-1, 5.28*106 copies.g-1, 4.44*106 copies.g-1 and the abundance of phoD gene in the three groups were $31.26 * 106$ copies.g-1, 8.11*106 copies.g-1, and 2.93*106 copies.g-1, respectively. Fig. 3 showed that the abundance of nosZ gene and phoD gene were significantly higher in $\mathrm{CC}$ than in CG and CS. Compared with the conventional shrimp culture mode, the shrimp-vegetation rotation system could significantly increase the abundance of nosZ and phoD genes in the sediment. Usually, nosZ and phoD were the marker genes of denitrifying bacteria and phosphate-solubilizing bacteria. It is predicted that the relative abundance of denitrifying bacteria and phosphate-solubilizing bacteria in shrimpvegetable rotation sediment may be more than that of uncultivated sediment.

\section{Sequencing Results and Diversity Indexes}

Hiseq 2500 was used to sequence the 16s rRNA gene of the soil bacteria. A total of 218108 original sequences were obtained from 15 samples with an average length of $40774 \mathrm{bp}$. The average length of reads in all samples was between 218 and 552 bp. The sequencing data covered a total of 27,747 unique tags. After tag formation, 7,182 OTUs were obtained (Table 2). As shown in Fig. 4a), the rarefaction curves

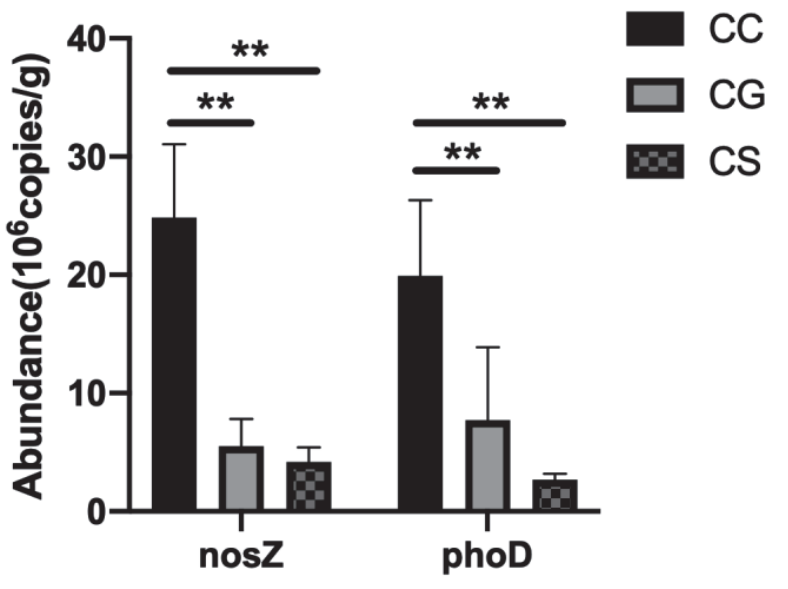

Fig. 3. Comparison of abundance of nosZ gene and phoD gene in differently treated sediment groups. ${ }^{*} \mathrm{P}<0.05$. 
Table 2. Sequencing results of different samples

\begin{tabular}{|c|c|c|c|}
\hline & $\begin{array}{c}\text { Sequence } \\
\text { number }\end{array}$ & $\begin{array}{c}\text { Base } \\
\text { number(bp) }\end{array}$ & OTUs \\
\hline CC1 & 33590 & 31042720 & 1997 \\
\hline CC2 & 32908 & 30092865 & 1820 \\
\hline CC3 & 36290 & 3354094 & 2464 \\
\hline CC4 & 30066 & 27909331 & 2054 \\
\hline CC5 & 31200 & 28855103 & 2233 \\
\hline CG1 & 36181 & 3340012 & 1691 \\
\hline CG2 & 37427 & 34588743 & 2368 \\
\hline CG3 & 42654 & 39553950 & 2134 \\
\hline CG4 & 31992 & 29584952 & 2431 \\
\hline CG5 & 35267 & 32612230 & 1975 \\
\hline CS1 & 32890 & 30409459 & 2484 \\
\hline CS2 & 35760 & 33072469 & 2453 \\
\hline CS3 & 37745 & 34882627 & 2453 \\
\hline CS4 & 33146 & 30654922 & 1958 \\
\hline CS5 & 38702 & 35793545 & 1978 \\
\hline Total & 525818 & 425747022 & 32493 \\
\hline & & & \\
\hline
\end{tabular}

tend to be flat and saturated, indicating that the amount of sequence data obtained at this sequencing depth is enough to reflect the diversity of soil sample microorganisms. The rank abundance curve showed that species richness reached a saturation point at a lower relative abundance level (Fig. 4b). Most of the 5 repeat samples in each group can be clustered together in the UPGMA result (Fig. 4c). Also, PLSDA results showed that the biological repeat samples in each group were gathered together, which indicated that an excellent internal consistency (Fig. 4d).

We calculated the Shannon, Simpson, chaol, and $\mathrm{ACE}$ indexes to evaluate the bacterial diversity of the soil samples in different groups (Table 3). And no significant difference found among the 3 groups. Shannon, Chaol index, and ACE index of CS were higher than $\mathrm{CC}$ and $\mathrm{CG}$, the difference was not significant; Simpson index of CS and CG were lower than CC. Besides, the OTUs numbers showed that there were more OTUs in $\mathrm{CS}$ than that in $\mathrm{CC}$ and $\mathrm{CG}$, and more OTUs in CG than that in CC (CC: 4493; CG: 5110; CS: 5856). Further, the Venn analysis showed that there were 3254 common OTUs between CC and CS; 150 common OTUs between CG and CS; 1506 common OTUs among all the three groups (Fig. 4e).
A

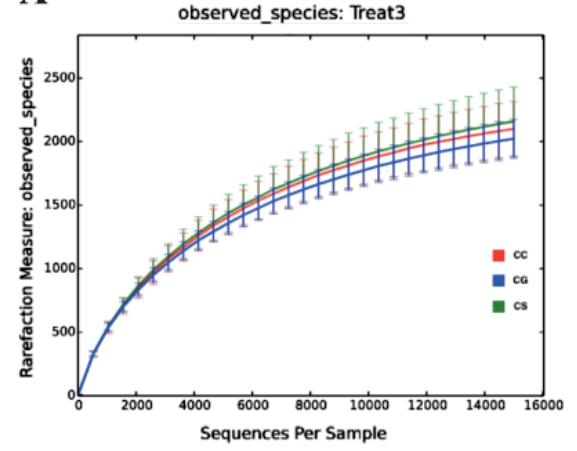

D

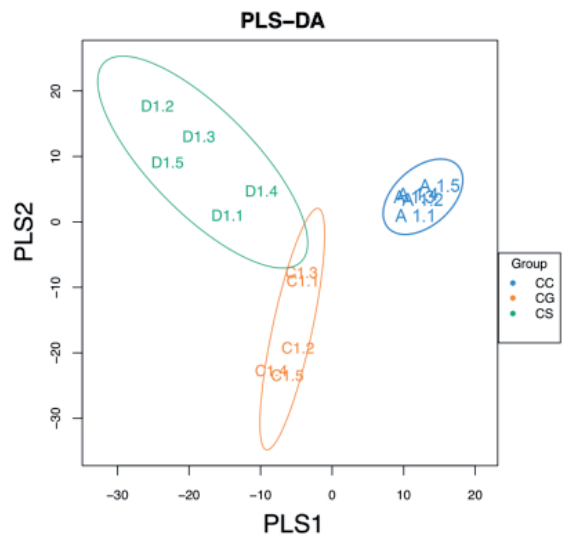

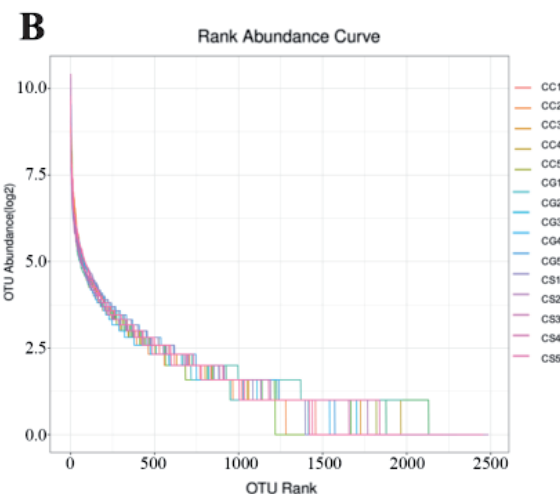

$\mathbf{E}$

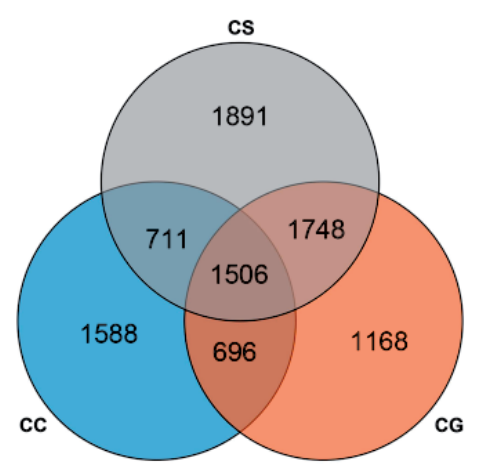

C

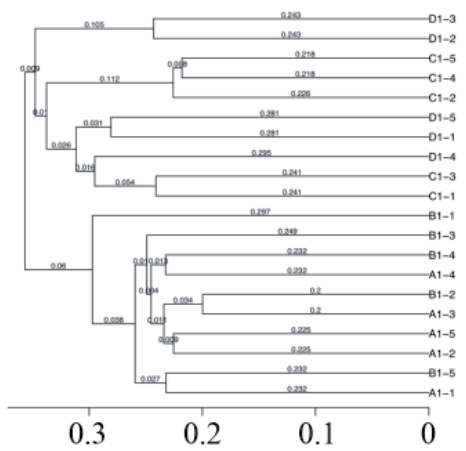

Fig. 4. Summary of sequence data. (A)-(C) The rarefaction curve, rank abundance curve and PLS-DA results of different samples, respectively. (D) The UPGMA results, which represents weighted unifrac distance of different samples. (E) Taxonomic composition of microbial species in different sediment samples. 


\section{Effects of Shrimp-Vegetable Rotation on the Taxonomic Distribution of Sediments}

First, we compared the number of bacteria communities contained in different treatment groups at each classification level (Fig. 5a, b). At the phylum level, Proteobacteria, Chloroflexi, Actinobacteria, Acidobacteria, Bacteroidetes, Gemmatimonadetes, Nitrospirae, Patescibacteria, Spirochetes, and Firmicutes were the top 10 most abundant (Fig. 5c). Of which the Proteobacteria, Actinobacteria, Gemmatimonadetes showed significantly higher abundances in CC and CG than CS. The abundance of Patescibacteria was highest in CC compared with the other groups. Conversely, abundances of the Chloroflexi and Nitrospirae in CS were significantly higher than in CC and CG (Table 4).

At genus level, the dominant bacteria of the top 20 abundant were Thiobacillus, RBG-16-58-14,
MND1, Thioalkalispira, Pseudomonas, Sulfurifustis, Nocardioides, Anaeromyxobacter and so on (Fig. 5d). The abundances of Thiobacillus, MND1, Sulfurifustis, Nocardioides, Gemmatimonas, and Dyellain CC were significantly higher than that in CS. Among them, MND1, Sulfurifustis, Nocardioidesin CG were significantly higher than CS. But RBG-16-58-14, Thioalkalispira, Pseudomonas had the opposite trends in the three groups (Table 5). Interestingly, it was found that an uncultured genus of the Anaerolineaceae family which had the significant differences in three groups. The abundances were $4.7 \%, 5.4 \%, 9.3 \%$ in CC, CG and CS groups, respectively and had the same family as one of the dominant bacteria (RBG-16-58-14). From the results, it is proved that shrimp-vegetable rotation can change the taxonomic distribution in pond sediment.
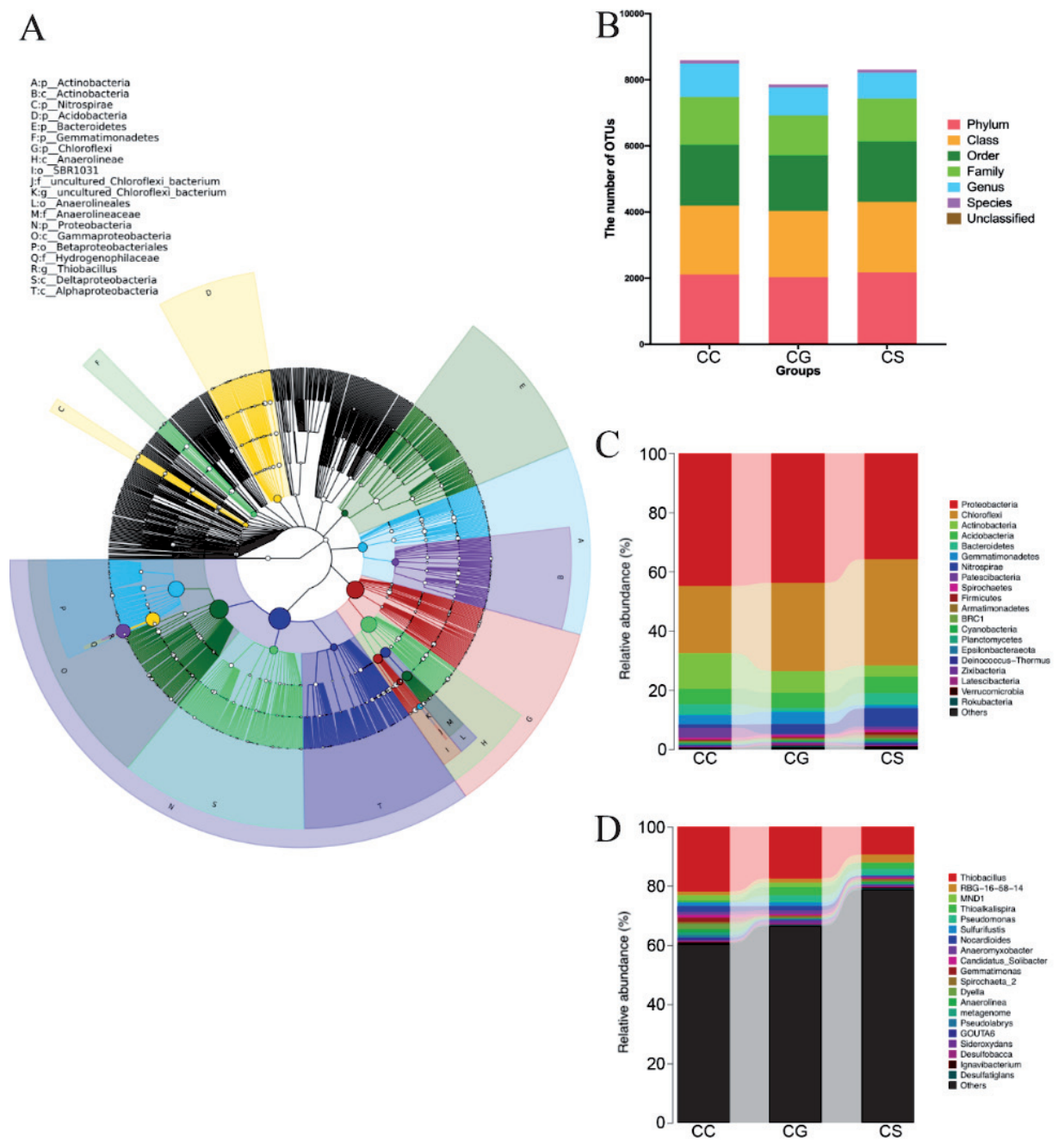

Fig. 5. Distribution results of microbial species at different levels. (A) The hierarchical relationship of all taxonomic units (represented by nodes) from the phylum to the genus (listed in order from the inner circle to the outer circle). The node size corresponds to the average relative abundance of the taxon. The top 20 taxon of relative abundance will also be lettered in the picture. (B) OTU classification and classification status statistical results. The ordinate is the number of OTUs in each sample that can be classified to the classification level of phylum, class, order, family, genus, and species. (C) The relative abundance of top 20 intestinal bacteria in all groups at phylum level; (D) The relative abundance of top 20 intestinal bacteria in all groups at genus level. 
Table 3. Alpha Diversity Indexes in CC, CG and CS groups.

\begin{tabular}{|c|c|c|c|c|}
\hline Groups & Shannon & Simpson & Chao1 & ACE \\
\hline CC & 9.346 & 0.994 & 2379.662 & 2477.506 \\
\hline CG & 9.296 & 0.993 & 2351.698 & 2432.288 \\
\hline CS & 9.38 & 0.993 & 2488.032 & 2606.592 \\
\hline
\end{tabular}

\section{Association Network Analysis and Metabolic Function Prediction}

A network analysis of the bacteria at genus level based on Spearman correlation coefficient $(\mathrm{R}>0.6$, $\mathrm{P}<0.01)$ was used to examine interactions between members of different communities which was displayed

Table 4. Significance of the microbial communities in different treatment groups at phylum level.

\begin{tabular}{|c|c|c|c|c|c|c|}
\hline & Proteobacteria & Actinobacteria & Gemmatimonadetes & Patescibacteria & Chloroflexi & Nitrospirae \\
\hline $\mathrm{CC}$ & $44.4 \% \mathrm{a}$ & $7.8 \% \mathrm{a}$ & $2.8 \% \mathrm{a}$ & $4.9 \% \mathrm{a}$ & $22.7 \% \mathrm{a}$ & $1.2 \% \mathrm{a}$ \\
\hline $\mathrm{CG}$ & $43.7 \% \mathrm{a}$ & $7.4 \% \mathrm{a}$ & $4.3 \% \mathrm{a}$ & $0.3 \% \mathrm{~b}$ & $29.7 \% \mathrm{a}$ & $3.2 \% \mathrm{a}$ \\
\hline $\mathrm{CS}$ & $35.7 \% \mathrm{~b}$ & $3.7 \% \mathrm{~b}$ & $1.2 \% \mathrm{~b}$ & $1.1 \% \mathrm{~b}$ & $36.0 \% \mathrm{~b}$ & $6.0 \% \mathrm{~b}$ \\
\hline
\end{tabular}

The data with different little letters indicated the significant difference at $5 \%$ level.
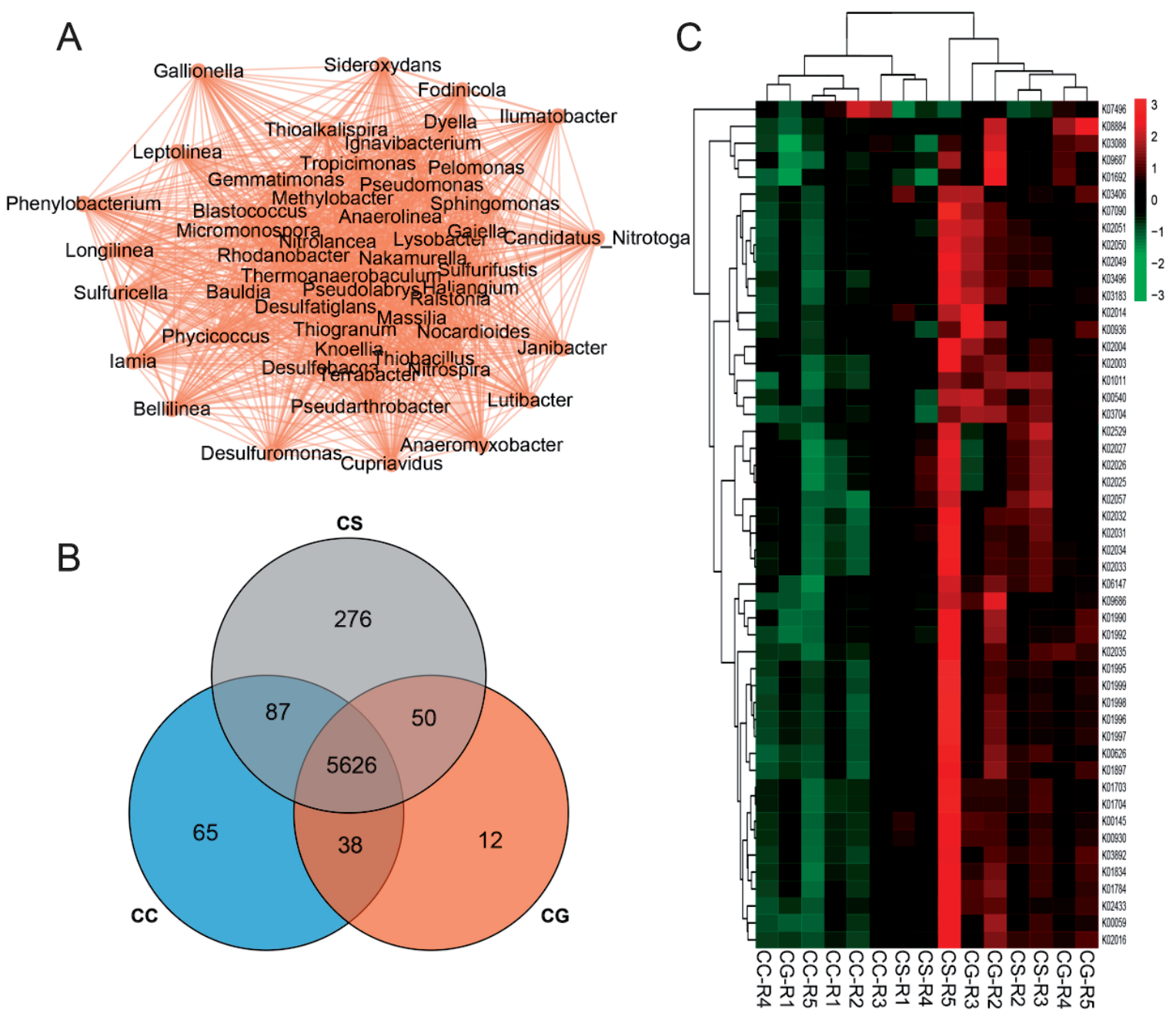

Fig. 6. Spearman network analysis and metabolic function prediction. (A) Association network diagram of dominant genus. Nodes represent the dominant genus. The connection between the nodes indicated that there was a correlation between the two genera. The red line indicates a positive correlation and the green line indicates a negative correlation. The more connections through a node, the more the genus is associated with other members of the flora. (B) Venn diagram of common functional units. Proportion of shared and unique functional units in CC, CG and CS groups. (C) Heat map of KEGG orthologous gene cluster abundance combined with cluster analysis. Red represents functional units with higher abundance in the corresponding sample, green represents functional units with lower abundance. 


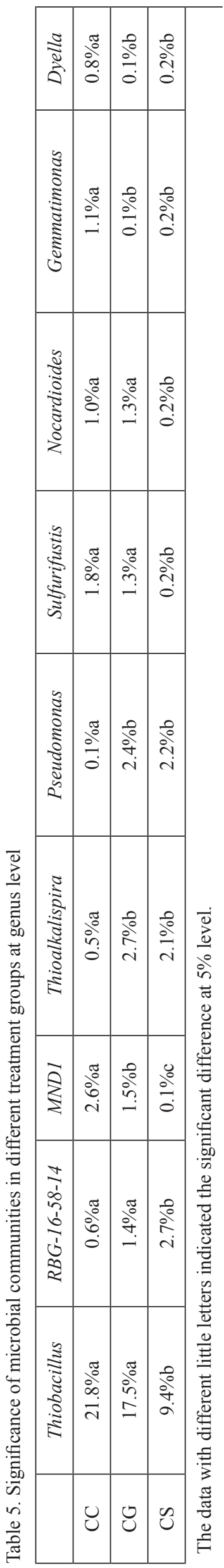

in Fig. 6a). Among the top 50 most abundant bacteria genus, Thermoanaerobaculum, Gemmatimonas, Phycicoccus, Fodinicola, Nitrolancea, Thiogranum, Longilinea, Pseudarthrobacter, Ignavibacterium showed more association with other members of the flora. Thermoanaerobaculum, Gemmatimonas, Phycicoccus, Fodinicola, Nitrolancea, Thiogranum, Pseudarthrobacter, Ignavibacteriumwere positively correlated with most other flora (red line). Instead, Longilineais negatively correlated with most other flora (green line).

According to the prediction results of PICRUSt, annotation information corresponding to each functional spectrum database could be obtained for each sample. Fig. 6b) presented the proportion of common and unique functional units of each treatment group. The number of functional units appearing in the three groups of $\mathrm{CC}, \mathrm{CG}$, and $\mathrm{CS}$ was 5,626 , and the number of unique functional units of CC, CG, and CS were 65, 12, 276, respectively. It proved that the microbial functionality of the CS group was significantly different from the other two groups. The heat map showed results of cluster analysis of the top 50 abundance functional units (Fig. 6c). Functional units with larger differences in abundance in the three groups were concentrated in the Cell Motility (Cellular Processes), Membrane Transport (Environment Information Processing), Translation (Genetic Information Processing), Energy Metabolism and Carbohydrate Metabolism (Metabolism) in KEGG level2 pathway.

\section{Discussion}

In the traditional aquaculture model, nutrient pollution is often caused [21], the nitrogen, phosphorus, and sulfide contained in the excreta and biological debris of farmed animals are the main pollutants $[22,23]$. Rotation is a common and important way to increase the output of food and aquatic products, and it has been widely used in agricultural products. Studies have shown that shrimp manure in rice and shrimp breeding mode can enhance soil fertility, reduce the use of chemical fertilizers, and improve farmland utilization efficiency and economic benefits while reducing production input. In the present study, it was found that shrimp-vegetative rotation could significantly increase the yield of shrimp farming. As we know, TN and TP are also widely used as indicators of water eutrophication [24]. The significant decline in TN and TP concentrations may be attributed to the sustained release of TN and TP in soil. $\mathrm{NH}_{4}^{+}$and $\mathrm{NO}_{2}^{-}$are ions that are usually part of the nitrogen cycle. The $\mathrm{NH}_{4}^{+}$in water was believed to originate from feces and excessive feed, which damaged the gills, increased the oxygen consumption, and affected the growth of shrimp [18]. In this study, at the end of shrimp culture, the content of TN, TC, and TP in the sediments of ponds increased significantly. By planting vegetables, the contents 
of the three elements in the sediment decreased sharply, and the removal rates reached $73.5 \%, 77.0 \%$, and $71.5 \%$, which provided a good ecological environment for the next shrimp farming.

At present, research on rotation compounding models have mostly focused on soil physical and chemical properties, greenhouse gases, and cultivation techniques. There has been less research on the soil denitrification microorganisms. Because nitric oxide reductase catalyzes is the final step of denitrification, the nosZ gene is also often used as a key functional gene for molecular markers to detect whether complete denitrification [25]. In the alkaline phosphatase family, the phoD gene is considered to be the most important alkaline phosphatase gene in soil [26, 27]. This study showed that shrimp-vegetative rotation significantly increased the abundance of nosZ and phoD genes in the sediment at the late planting stage, which indicated that changes in tillage patterns will affect the abundance and diversity of denitrifying bacteria and alkaline phosphatase metabolizing flora in pond sediments. Previous studies showed that the increases in the abundance of Alpha proteobacteria by $\mathrm{P}$ inputs in our study indicate the determinants of $\mathrm{P}$ availability to some typical microorganisms with phoD/phoA genes, and that the increased $\mathrm{P}$ supply favored the growth of copiotrophic microorganisms that contained phoD/phoA such as Proteobacteria [28-30]. This theory may also be applicable to this study.

The alpha diversity index showed that shrimpvegetation rotation did not significantly change the microbial diversity of the sediment, which was consistent with other previous studies [25, 31]. There are differences in the microbial community structure between the experimental group and the control group, but still retaining similarity in the community structure. The dominant phylum in all three groups were Proteobacteria, Chloroflexi, Actinobacteria, Acidobacteria, Bacteroidetes, Gemmatimonadetes, Nitrospirae, Patescibacteria, Spirochaetes, and Firmicutes. Our results showed that the taxonomic distributions of microbial communities were different at different levels of classification. The abundance of Proteobacteria, Actinobacteria, Gemmatimonadetes, Chloroflexi, Nitrospirae showed the particularity of the farming system of rotation combine with fallow and flood. Among them, Chloroflexi and Nitrospirae is the phylum where typical nitrifying bacteria are located. And the majority of denitrifying bacteria are concentrated in the Proteobacteria class of the Proteobacteria phylum [32]. Gemmatimonadetes has a strong denitrification function, and its relative abundance decreases with increasing nitrogen levels [33]. At genus level, the abundance of Thiobacillus was significantly higher in the shrimp-vegetable rotation group than in the control group. Thiobacillusis common autotrophic denitrifying bacteria, which can use carbon dioxide, organic matter and sulfur compounds as energy sources [34, 35]. And Gemmatimonas is also closely related with denitrification function. Interestingly, the common denitrifying bacteria, Pseudomonas, appears to have the opposite trend. This may be due to the different tolerance of some denitrifying bacteria to dissolved oxygen (DO) [36]. In our study, it was found that an uncultured genus of the Anaerolineaceae family which had the significant differences in shrimp-vegetation rotation group and control group. Anaerolineaceae not only has the function of denitrification, but also degrades carbohydrates and other cellular materials such as amino acids [37]. It can be speculated that it also played an important role in improving the removal rate of $\mathrm{TN} \mathrm{TP}$ in the cultivation area. Increased abundance of denitrifying bacteria confirms results of increased copy number of nosZ and phoD genes. The aforementioned bacteria showed great beneficial effects on the pond sediments of cultured shrimp, such as reducing the content of nutrient elements in the soil, changing nitrate to nitrite, and then nitrogen; cleaning up toxic substances; increase shrimp production. Flora metabolic function prediction and cluster analysis results displayed that the bacteria genus mentioned above may play a role in regulating cell motility, membrane transport, translation, energy metabolism and carbohydrate metabolism pathways. From these results, we speculate that the shrimp-vegetable rotation system accelerated the ammonia nitrogen cycle and greatly promoted the restoration of the soil microbial system. The changes in the abundance of nitrifying bacteria and denitrifying bacteria are an important manifestation of this process.

Various environmental factors in nature, such as $\mathrm{pH}$, soil oxygen content [38, 39], soil temperature [40], soil moisture content [40], nutrient supply status [39], and plant species [38, 41] can affect the structure of denitrifying bacterial communities. Therefore, it is necessary to further study the main factors affecting denitrification activity, and the microbial mechanism of the functional gene community structure related to denitrification, so as to use it in the rotation mode. There were a lot of unknown bacteria, which needs more work to be done to learn about them, it is hard to find everything in this study alone. Due to the complex soil environment of shrimp-vegetable rotation, which has undergone alternating wet and dry phases, the study of denitrifying bacteria communities in shrimpvegetable soil is more complicated and requires more in-depth systematic research.

The application of the shrimp-vegetable rotation system has achieved remarkable results, especially at the economic level, but its mechanism needs more exploration. This present study opened the exploration of the mechanism of the advantage of the shrimp-vegetable rotation system, which will provide a scientific basis for the application of the shrimp-vegetable rotation system. Based on the prediction of the metabolic function of the soil microbiota, the present results it can guide the experimental design of metagenomic sequencing and more rationally screen samples for subsequent research. 
Due to limited conditions, this study cannot reveal whether different latitudes have a significant impact on the application of shrimp-vegetable rotation system, which had become a limitation of this study. More work is needed for the promotion and scientific application of the shrimp-vegetable rotation system.

\section{Conclusion}

Shrimp-vegetable rotation had stronger restoration ability of soil bacterial diversity and soil fertility than the other two farming mode. The rotation mode promoted a good ammonia nitrogen cycle. The changes in the abundance of nitrifying bacteria and denitrifying bacteria are an important manifestation of this process. This study will provide a scientific basis and data support for the application of shrimp vegetable rotation. However, due to the complex soil environment of shrimp and vegetable rotation, the community of nitrifying and denitrifying bacteria in the soil is extremely complex, so more work is needed to reveal the soil change mechanism.

\section{Acknowledgments}

This work was supported by the China Agriculture Research System (Grant no. CARS-48), the Science and Technology Planning Project of Fujian Provincial (Grant no. 2018N5007).

\section{Conflict of Interest}

The authors have no conflicts of interest with respect to the research, authorship and/or publication of this article.

\section{Data Availability Statement}

The high-throughput sequencing data reported in this paper have been deposited in the NCBI under accession number PRJNA692676, that is publicly accessible at https://dataview.ncbi.nlm.nih.gov.

\section{References}

1. THRALL P.H., BEVER J.D., BURDON J.J. Evolutionary change in agriculture: the past, present and future. Evolutionary Applications, 3, 405, 2010.

2. WAN N.F., LI S.X., LI T., CAVALIERI A., WEINER J., ZHENG X.Q., JI X.Y., ZHANG J.Q., ZHANG H.L., ZHANG H. Ecological intensification of rice production through rice-fish co-culture. Journal of Cleaner Production, 234, 1002, 2019.

3. RAY K., BANERJEE H., DUTTA S., SARKAR S., MURRELL T.S., SINGH V.K., MAJUMDAR
K. Macronutrient management effects on nutrient accumulation, partitioning, remobilization, and yield of hybrid maize cultivars. Frontiers in plant science, 11, 1307, 2020.

4. BRIGGS K.B., HARTMANN V.A., YEAGER K.M., SHIVARUDRAPPA S., DíAZ R.J., OSTERMAN L.E., REED A.H. Influence of hypoxia on biogenic structure in sediments on the Louisiana continental shelf. Estuarine. Coastal and Shelf Science, 164, 147, 2015.

5. GIORGINI M., MIGUEZ A., ESQUIUS K.S., DE ASTARLOA C.D., IRIBARNE O., FANJUL E., ESCAPA M. Regenerative bioturbation by intertidal burrowing crabs modifies microphytobenthic composition and enhances primary production in SW Atlantic mudflats. Marine Ecology Progress Series, 632, 43, 2019.

6. CHUMNANKA N., BOYD C.E., VIRIYATUM R., TUNKIJJANUKIJ S. Bottom soil characteristics, survival and production of shrimp in low-salinity, inland ponds in Alabama and Florida (USA). Journal of Soils and Sediments, 15 (3), 671, 2015.

7. BOOPATHY R. Waste Treatment in Recirculating Shrimp Culture Systems. Sustainable Aquaculture, 1, 301, 2018.

8. JUHANSON J., HALLIN S., SöDERSTRöM M., STENBERG M., JONES C.M. Spatial and phyloecological analyses of nosZ genes underscore niche differentiation amongst terrestrial $\mathrm{N} 2 \mathrm{O}$ reducing communities. Soil Biology and Biochemistry, 115, 82, 2017.

9. YANG Y., ZHAO J., JIANG Y., HU Y., ZHANG M., ZENG Z. Response of bacteria harboring nirS and nirK genes to different $\mathrm{N}$ fertilization rates in an alkaline northern Chinese soil. European Journal of Soil Biology, 82, 1, 2017.

10. SAEKI Y., NAKAMURA M., MASON M.L.T., YANO T., SHIRO S., SAMESHIMA-SAITO R., ITAKURA M., MINAMISAWA K., YAMAMOTO A. Effect of flooding and the nosZ gene in bradyrhizobia on bradyrhizobial community structure in the soil. Microbes and environments, 32 (2), 154, 2017.

11. CUKER B.E., CORNWELL J., The Journey from Peruvian Guano to Artificial Fertilizer Ends with Too Much Nitrogen in the Chesapeake Bay, in Diet for a Sustainable Ecosystem, 1, 177, 2020.

12. JIN Z.J., LI L.Q., LIU X.Y., PAN G.X., QAISER H., LIU Y.Z. Impact of long-term fertilization on community structure of ammonia oxidizing and denitrifying bacteria based on amoA and nirK genes in a rice paddy from Tai Lake Region, China. Journal of Integrative Agriculture, 13 (10), 2286, 2014.

13. LIGI T., TRUU M., TRUU J., NõLVAK H., KAASIK A., MITSCH W.J., MANDER Ü. Effects of soil chemical characteristics and water regime on denitrification genes (nirS, nirK, and nosZ) abundances in a created riverine wetland complex. Ecological Engineering, 72, 47, 2014.

14. YIN C., FAN F., SONG A., LI Z., YU W., LIANG Y. Different denitrification potential of aquic brown soil in Northeast China under inorganic and organic fertilization accompanied by distinct changes of nirS-and nirKdenitrifying bacterial community. European journal of soil biology, 65, 47, 2014.

15. WAHEED H., HASHMI I., NAVEED A.K., KHAN S.J. Molecular detection of microbial community in a nitrifying-denitrifying activated sludge system. International Biodeterioration \& Biodegradation, 85, 527, 2013. 
16. DEVOL A.H. Denitrification, anammox, and N2 production in marine sediments. Annual review of marine science, 7, 403, 2015.

17. HOU S., AI C., ZHOU W., LIANG G., HE P. Structure and assembly cues for rhizospheric nirK-and nirS-type denitrifier communities in long-term fertilized soils. Soil Biology and Biochemistry, 119, 32, 2018.

18. NI M., YUAN J., HUA J., LIAN Q., GUO A., LIU M., XIN J., WANG H., GU Z. Shrimp-vegetable rotational farming system: An innovation of shrimp aquaculture in the tidal flat ponds of Hangzhou Bay, China. Aquaculture, 518, 734864, 2020.

19. PHAM T.A.N., LOC H.H., TRAN D.D., QUAN N.H. The inefficiency of Vietnamese prawn-rice rotational crops: A slacks-based data envelopment analysis. Journal of Agribusiness in Developing and Emerging Economies, 2020.

20. FAULKNER S., PATRICK JR W., GAMBRELL R. Field techniques for measuring wetland soil parameters. Soil Science Society of America Journal, 53 (3), 883, 1989.ce in paddy soil profile with different fertilizer regimes. Applied Soil Ecology, 84 (1), 38. 2014.

21. WANG M., XIONG X., LIU J., HE C., ZHAO Q. Carbon and Nitrogen Stable Isotopes Evidence for the Environmental Impact of the Cage Fish Farm in Poyang Lake, China. Bulletin of Environmental Contamination and Toxicology, 105 (6), 860, 2020.

22. MAWI S., KRISHNAN S., DIN M.F.M., ARUMUGAM N., CHELLIAPAN S. Bioremediation potential of macroalgae Gracilaria edulis and Gracilaria changii cocultured with shrimp wastewater in an outdoor water recirculation system. Environmental Technology \& Innovation, 17, 100571, 2020.

23. ZHONG X., ZHU Y., WANG Y., ZHAO Q., HUANG $\mathrm{H}$. Effects of three antibiotics on growth and antioxidant response of Chlorella pyrenoidosa and Anabaena cylindrica. Ecotoxicology and Environmental Safety, 211, 111954, 2021.

24. BALCI M., BALKIS N. Assessment of phytoplankton and environmental variables for water quality and trophic state classification in the Gemlik Gulf, Marmara Sea (Turkey). Marine pollution bulletin, 115 (1-2), 172, 2017.

25. RICH J., HEICHEN R., BOTTOMLEY P., CROMACK JR K., MYROLD D. Community composition and functioning of denitrifying bacteria from adjacent meadow and forest soils. Applied and environmental microbiology, 69 (10), 5974, 2003.

26. LUO G., LING N., NANNIPIERI P., CHEN H., RAZA W., WANG M., GUO S., SHEN Q. Long-term fertilisation regimes affect the composition of the alkaline phosphomonoesterase encoding microbial community of a vertisol and its derivative soil fractions. Biology and Fertility of Soils, $\mathbf{5 3}$ (4), 375, 2017.

27. KATHURIA S., MARTINY A.C. Prevalence of a calciumbased alkaline phosphatase associated with the marine cyanobacterium Prochlorococcus and other ocean bacteria. Environmental microbiology, 13 (1), 74, 2011.

28. DAI Z., LIU G., CHEN H., CHEN C., WANG J., AI S., WEI D., LI D., MA B., TANG C., BROOKES P.C., XU J. Long-term nutrient inputs shift soil microbial functional profiles of phosphorus cycling in diverse agroecosystems. The ISME journal, 14 (3), 757, 2020.

29. TAN H., BARRET M., MOOIJ M.J., RICE O., MORRISSEY J.P., DOBSON A., GRIFFITHS B.,
O'GARA F. Long-term phosphorus fertilisation increased the diversity of the total bacterial community and the phoD phosphorus mineraliser group in pasture soils. Biology and Fertility of Soils, 49 (6), 661, 2013.

30. RAGOT S.A., KERTESZ M.A., MéSZáROS É., FROSSARD E., BüNEMANN E.K. Soil phoD and phoX alkaline phosphatase gene diversity responds to multiple environmental factors. FEMS microbiology ecology, 93 (1), fiw 212,2017

31. RICH J.J., MYROLD D.D. Community composition and activities of denitrifying bacteria from adjacent agricultural soil, riparian soil, and creek sediment in Oregon, USA. Soil Biology and Biochemistry, 36 (9), 1431, 2004.

32. JI B., YANG K., ZHU L., JIANG Y., WANG H., ZHOU J., ZHANG H. Aerobic denitrification: a review of important advances of the last 30 years. Biotechnology and bioprocess engineering, 20 (4), 643, 2015.

33. GUO Y., GONG H., GUO X. Rhizosphere bacterial community of Typha angustifolia L. and water quality in a river wetland supplied with reclaimed water. Applied microbiology and biotechnology, 99 (6), 2883, 2015.

34. JASPER J.T., JONES Z.L., SHARP J.O., SEDLAK D.L. Nitrate removal in shallow, open-water treatment wetlands. Environmental science \& technology, 48 (19), 11512, 2014.

35. HU B., QUAN J., HUANG K., ZHAO J., XING G., WU P., CHEN Y., DING X., HU Y. Effects of $\mathrm{C} / \mathrm{N}$ ratio and dissolved oxygen on aerobic denitrification process: A mathematical modeling study. Chemosphere, 272, 129521, 2021.

36. JI B., WANG H., YANG K. Tolerance of an aerobic denitrifier (Pseudomonas stutzeri) to high $\mathrm{O}_{2}$ concentrations. Biotechnology letters, 36 (4), 719, 2014.

37. SUN L., TOYONAGA M., OHASHI A., MATSUURA N., TOURLOUSSE D.M., MENG X.-Y., TAMAKI H., HANADA S., CRUZ R., YAMAGUCHI T. Isolation and characterization of Flexilinea flocculi gen. nov., sp. nov., a filamentous, anaerobic bacterium belonging to the class Anaerolineae in the phylum Chloroflexi. International journal of systematic and evolutionary microbiology, $\mathbf{6 6}$ (2), 988, 2016.

38. BRIONES A.M., OKABE S., UMEMIYA Y., RAMSING N.-B., REICHARDT W., OKUYAMA H. Influence of different cultivars on populations of ammonia-oxidizing bacteria in the root environment of rice. Applied and Environmental Microbiology, 68 (6), 3067, 2002.

39. NICOLAISEN M.H., RISGAARD-PETERSEN N., REVSBECH N.P., REICHARDT W., RAMSING N.B. Nitrification-denitrification dynamics and community structure of ammonia oxidizing bacteria in a high yield irrigated Philippine rice field. FEMS microbiology ecology, 49 (3), 359, 2004.

40. WERTZ S., GOYER C., ZEBARTH B.J., BURTON D.L., TATTI E., CHANTIGNY M.H., FILION M. Effects of temperatures near the freezing point on $\mathrm{N} 2 \mathrm{O}$ emissions, denitrification and on the abundance and structure of nitrifying and denitrifying soil communities. FEMS microbiology ecology, 83 (1), 242, 2013.

41. JIANG X., YAO L., GUO L., LIU G., LIU W. Multi-scale factors affecting composition, diversity, and abundance of sediment denitrifying microorganisms in Yangtze lakes. Applied microbiology and biotechnology, 101 (21), 8015, 2017. 


\section{Supplementary Material}

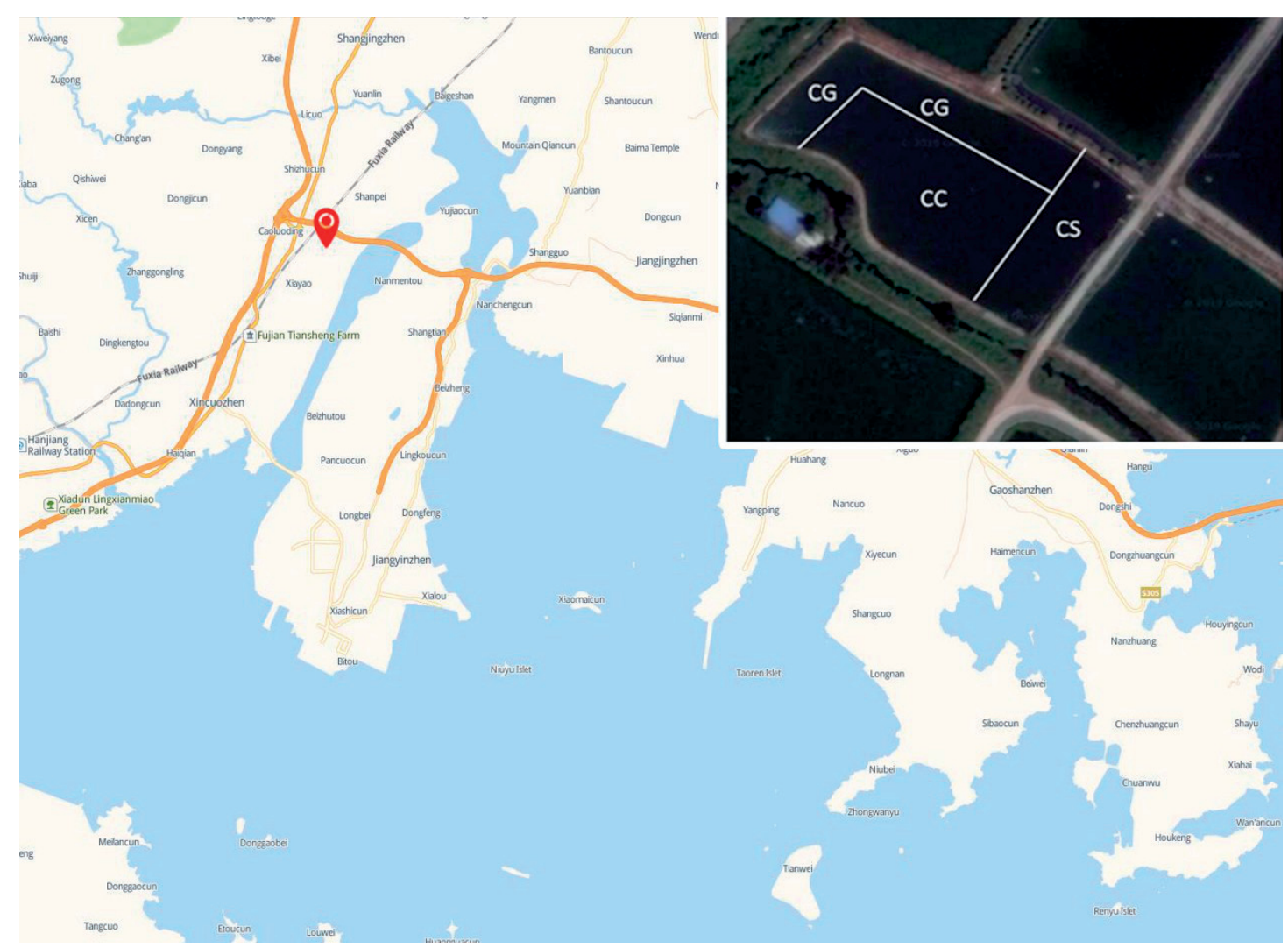

Fig. S1. Distribution chart of experimental design.
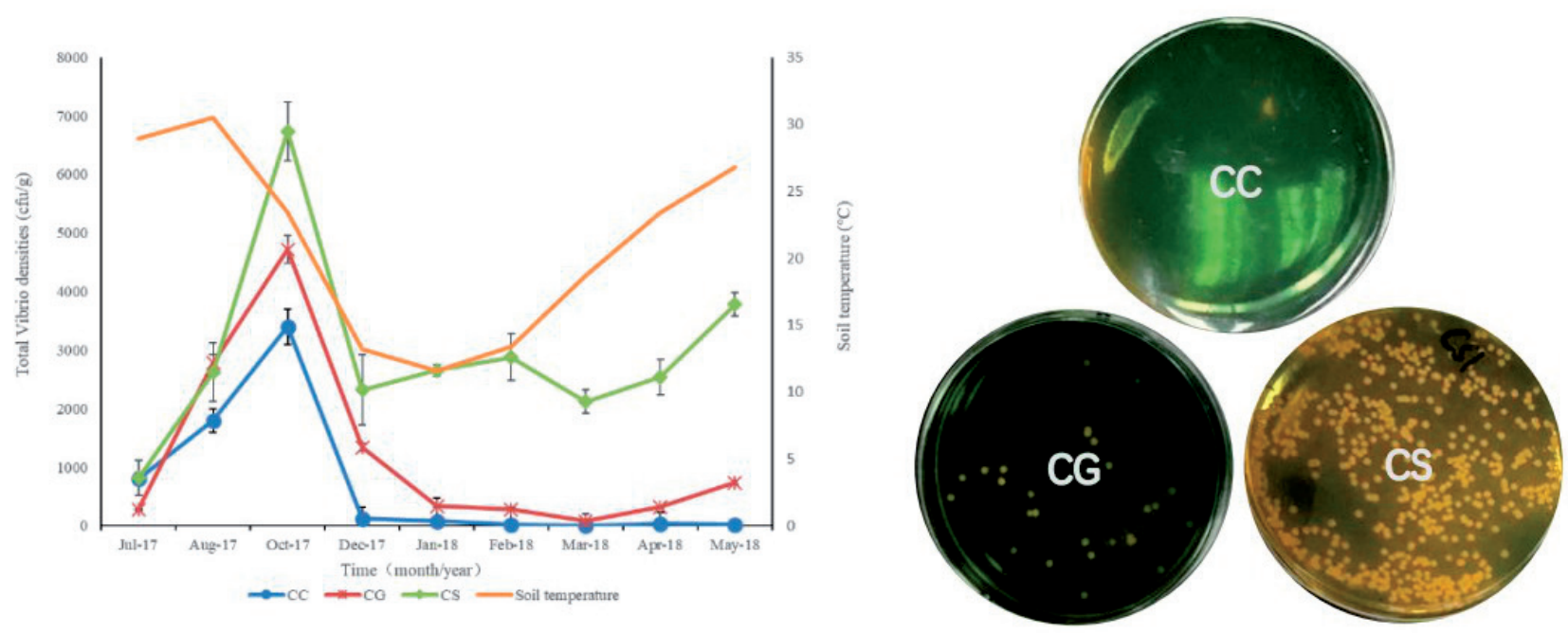

Fig. S2. The total vibrio densities (cfu/g) and soil temperature. Changes of soil temperature and the total vibrio densities in CC, CG and CS groups of the shrimp-vegetable rotation.

Group CC: cultivated area; Group CG: uncultivated area; Group CS: flooded area. 